\title{
Characteristics of selected quality parameters of the swimming pools port in Swinoujscie
}

\section{Charakterystyka wybranych parametrów jakości wód w basenach portowych w Świnoujściu}

\author{
Emil Cyraniak ${ }^{1}$, Piotr Daniszewski ${ }^{2}$, Beata Draszawka - Bołzan ${ }^{3}$ \\ ${ }^{1}$ Zarząd Morskich Portów Szczecin i Świnoujście S.A. \\ Laboratorium Badań Środowiska i Higieny Pracy, ul. Bytomska 7, 70-603 Szczecin, Poland \\ ${ }^{2}$ Katedra Zoologii Bezkręgowców i Limnologii, Wydział Biologii, Uniwersytet Szczeciński \\ ul. Wąska 13, 71-415 Szczecin, Poland, \\ ${ }^{3}$ Katedra Chemii i Ochrony Środowiska Wodnego, Wydział Biologii, Uniwersytet Szczeciński \\ ul. Felczaka 3C, 71-412 Szczecin, Poland \\ E-mail address: daniszewski@univ.szczecin.pl
}

\begin{abstract}
To estimate differentiation of water chemistry in reservoirs of swimming pools port in Świnoujście, in time of 2004 - 2008. In arbitrary appointed times 5 physical and chemical indicators of water quality were determined to evaluate general status and water condition - temperature, $\mathrm{pH}, \mathrm{NO}_{3}{ }^{-}$, $\mathrm{PO}_{4}{ }^{3-}, \mathrm{P}_{\text {tot. }}$. Port of Świnoujście is a sea port located on the Gulf of Pomorską, on the southern coast of the Baltic Sea, on the islands of Usedom and Wolin. The Port is located at the Świna, in Świnoujście, West Pomeranian Voivodeship. The port can be placed on ships with a maximum length of $42.0 \mathrm{~m}$ and width $260,0 \mathrm{~m}$, draught $12.8 \mathrm{~m}$. The tides in the Harbor, but the water level fluctuations are possible with sudden currents entering and outgoing, which depending on the direction of prevailing winds and reaching speeds of up to 1.5 knots. At the entrance to the port at the West breakwater, It is Western.

The primary function of the port of Świnoujście is the transshipment of cereals, ores, oil, paper, cellulose, general cargo, coal, iron. Trying to test water were collected by PN/C-04632.03 with a depth of about. $0.5 \mathrm{~m}$ below the water surface. The temperature at the place of sampling were numbered, $\mathrm{pH}$. Collected water samples were fixed in accordance with the recommendations in the Polish StandardPN/C-04632.04. Other indicators for the quality of the waters have been tagged within 24 hours from the moment of download attempts. The quality objectives was evaluated according to the criteria recommended to evaluate inland surface waters referred to in regulation of the Minister of the environment of 11 February 2004 on the classification for the present status of surface water and groundwater, how to conduct monitoring and how to interpret the results and presentation of these waters. Due to the exposure of the docks the port Świnoujście on the pollution associated with crosswhat are the cereals, ores, oil, cellulose, carbon, iron, general research evaluation of the water quality of these pools, you can assess the status of water in order to keep these waters.
\end{abstract}

Keywords: swimming pools port; natural water quality; temperature; $\mathrm{pH}, \mathrm{NO}_{3}{ }^{-} ; \mathrm{PO}_{4}{ }^{3-} ; \mathrm{P}_{\text {tot }}$ 


\section{STRESZCZENIE}

Celem niniejszej pracy było prześledzenie w okresie od 2004 do 2008 roku poziomu oraz dynamiki zmian w wodach basenów portowych Portu Świnoujście parametrów ogólnych jakości wód. W pracy oznaczano wskaźniki ogólne wody: temperaturę, $\mathrm{pH}, \mathrm{NO}_{3}{ }^{-}, \mathrm{PO}_{4}{ }^{3-}, \mathrm{P}_{\text {og. }}$. Wszystkie oznaczenia i obliczenia wykonywano według metod zalecanych przez Polskie Normy, stosując procedury analityczne opisane m.in. przez Dojlido, Elbanowska, Hermanowicza. Port Świnoujście jest to port morski położony nad Zatoką Pomorską, na południowym wybrzeżu Morza Bałtyckiego, na wyspach Uznam i Wolin. Port usytuowany w cieśninie Świny, w Świnoujściu, w województwie zachodniopomorskim. Do portu mogą być wprowadzane statki o maksymalnej długości $260,0 \mathrm{~m}$, szerokości 42,0 m i zanurzeniu $12,8 \mathrm{~m}$. Pływy w porcie nie występują, ale możliwe są wahania poziomu wody z nagłymi prądami wchodzącymi oraz wychodzących, które w zależności od kierunku wiatrów i osiągać prędkość do 1,5 węzła. Przy wejściu do portu przy zachodnim falochronie, znajduje się Mielizna Zachodnia. Podstawową funkcją Portu w Świnoujściu jest przeładunek zboża, rud, olejów, papieru, celulozy, drobnicy, węgla, żelaza. Próby wody do badań pobierano według PN/C04632.03 z głębokości ok. 0,5 m poniżej lustra wody. W miejscu poboru prób oznaczano temperaturę, $\mathrm{pH}$. Pobrane próbki wody zostały utrwalane zgodnie z zaleceniami zawartymi w Polskiej Normie PN/C-04632.04. Pozostałe wskaźniki określające jakość wód zostały oznaczone w przeciągu 24 godzin od momentu pobrania prób. Poszczególne wskaźników jakości wód oceniano według kryteriów zalecanych do oceniania śródlądowych wód powierzchniowych określonych w Rozporządzeniu Ministra Środowiska z dnia 11 lutego 2004 r. w sprawie klasyfikacji dla prezentowania stanu wód powierzchniowych i podziemnych, sposobu prowadzenia monitoringu oraz sposobu interpretacji wyników i prezentacji stanu tych wód. Z uwagi na narażenie basenów portowych Portu Świnoujście na zanieczyszczenia związane z przeładunkami jakie odbywają się na jego terenie zboża, rud, olejów, celulozy, drobnicy węgla, żelaza, należy prowadzić badania oceny jakości wód tych basenów, aby można na bieżąco ocenić stan wód tych akwenów.

Slowa kluczowe: baseny portowe, jakość wód, temperatura, $\mathrm{pH}, \mathrm{NO}_{3}^{-}, \mathrm{PO}_{4}^{3-}, \mathrm{P}_{\mathrm{og}}$.

\section{WPROWADZENIE}

Zgodnie z Ramową Dyrektywą Wodną, do 2015 r. wszystkie wody, w tym również w akwenach portowych, powinny mieć dobry stan ekologiczny [1-3, 6-9, 12, 15, 16, 19].

Baseny portowe należą do akwenów, których wody są szczególnie narażone na zanieczyszczenia $\mathrm{w}$ związku z przeładunkami jakie maja miejsce na ich terenie $[11,13,20$, 21, 24-26]. Baseny portowe należą do akwenów, których wody są szczególnie narażone na zanieczyszczenia $\mathrm{W}$ związku z przeładunkami jakie maja miejsce na ich terenie $[11,13,20$, 21, 24-26]. Podstawową funkcją Portu w Świnoujściu jest przeładunek zboża, rud, olejów, papieru, celulozy, drobnicy, węgla, żelaza [20, 21, 24-28].

\section{CZESŚĆ DOŚWIADCZALNA}

Badania zostały przeprowadzone na terenie 3 basenów portowych Portu Świnoujście (Baseny: Bałtycki, Atlantycki, i Zachodni) w miesiącach czerwiec - wrzesień 2004 - 2008. Port Świnoujście jest to port morski położony nad Zatoką Pomorską, na południowym wybrzeżu Morza Bałtyckiego, na wyspach Uznam i Wolin [25-28]. Port usytuowany w cieśninie Świny, w Świnoujściu, w województwie zachodniopomorskim [25-28].

Do portu mogą być wprowadzane statki o maksymalnej długości $260,0 \mathrm{~m}$, szerokości 42,0 $\mathrm{m}$ i zanurzeniu $12,8 \mathrm{~m}$ [25-28]. 
Pływy w porcie nie występują, ale możliwe są wahania poziomu wody z nagłymi prądami wchodzącymi oraz wychodzących, które w zależności od kierunku wiatrów i osiągać prędkość do 1,5 węzła [25-28]. [25-28].

Przy wejściu do portu przy zachodnim falochronie, znajduje się Mielizna Zachodnia

Podczas zimy, port jest zazwyczaj wolny od lodu. Zalodzenie basenów portowych i redy występuje dopiero po okresach długotrwałych mrozów [25-28].

Na mapie nr 1, przedstawiono usytuowanie Portu w Świnoujściu.

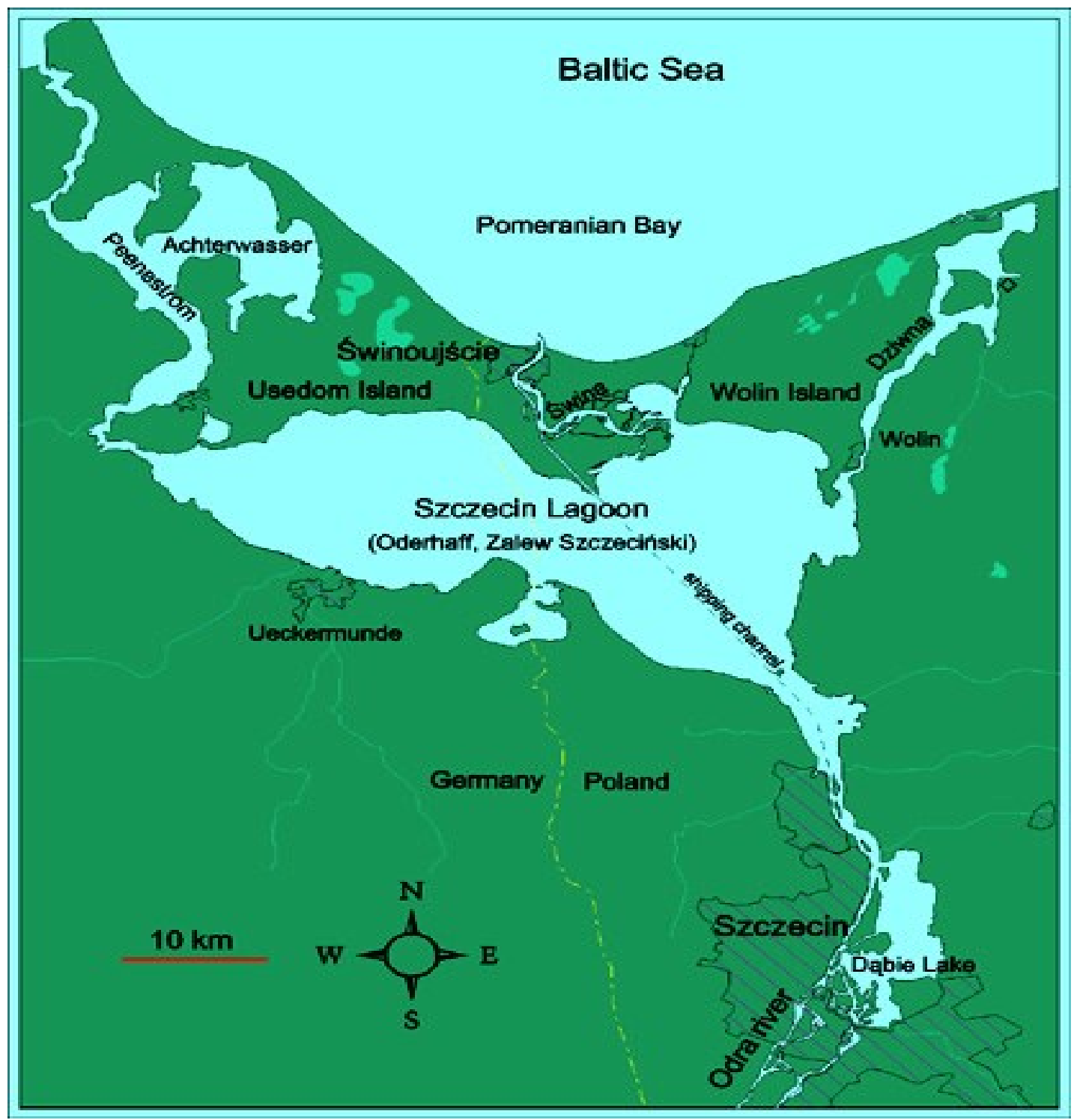

Mapa 1. Usytuowanie Portu w Świnoujściu. Źródto: Urząd Morski w Szczecinie

Na mapie nr 2 przedstawiono rozmieszczenie kanałów i nabrzeży Portu w Świnoujściu. 


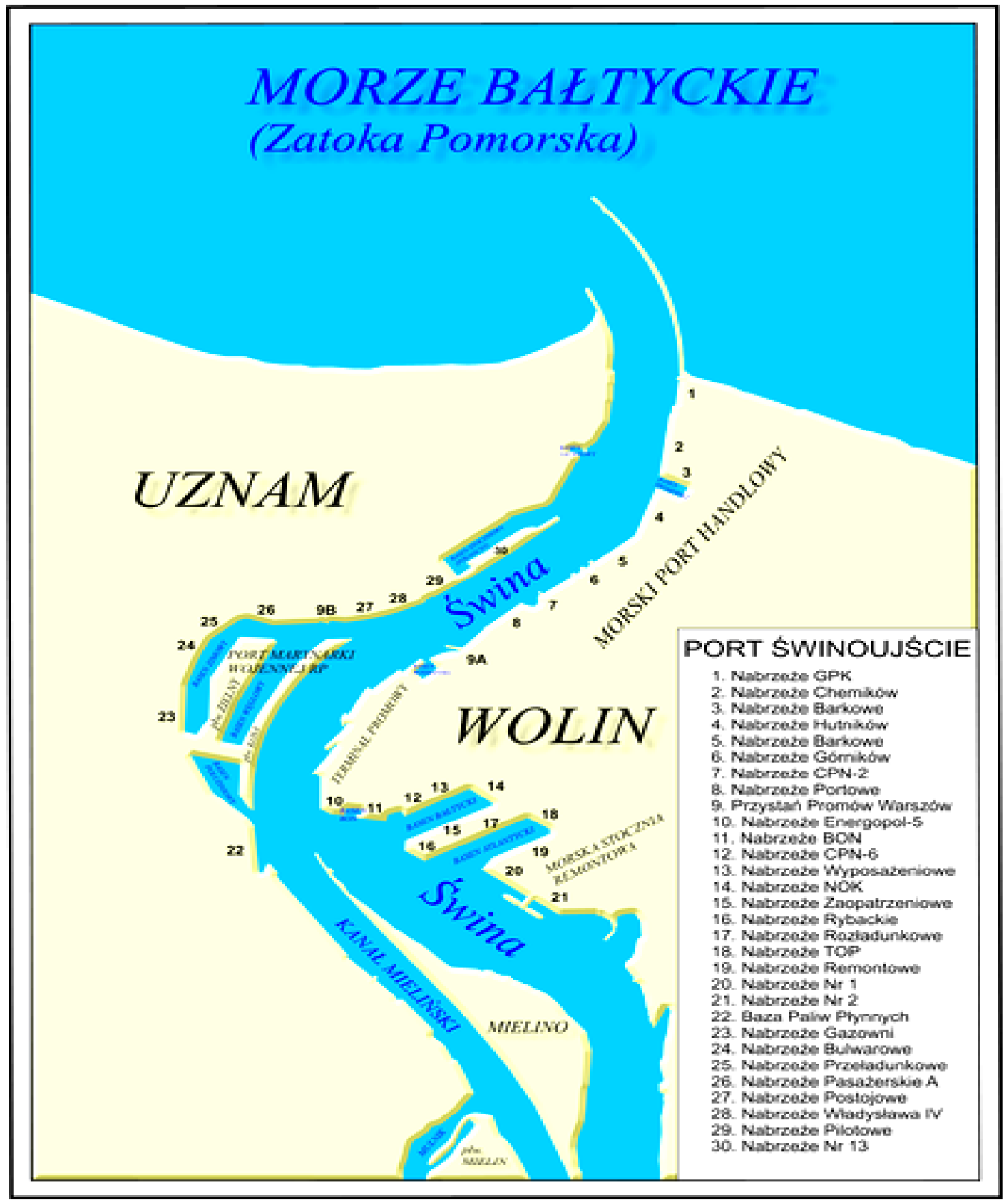

Mapa 2. Rozmieszczenie kanałów i nabrzeży Portu w Świnoujściu. Źródto: Zarząd Portów SzczecinŚwinoujście

Próby wody do badań pobierano według PN/C-04632.03 z głębokości ok. 0,5 m poniżej lustra wody. W miejscu poboru prób oznaczano temperaturę, $\mathrm{pH}$. Pobrane próbki wody zostały utrwalane zgodnie z zaleceniami zawartymi w Polskiej Normie - PN/C04632.04. Pozostałe wskaźniki określające jakość wód zostały oznaczone w przeciągu 24 godzin od momentu pobrania prób. W niniejszej pracy spośród wskaźników trofii wód oznaczono stężenie $\mathrm{NO}_{3}{ }^{-}$- zgodnie z PN/C-04576.09, $\mathrm{PO}_{4}{ }^{3-}$ rozp - zgodnie z PN/C-04537.02 i $\mathrm{P}_{\mathrm{og}}$ - zgodnie z PN/C-04537.09. Poszczególne wskaźników jakości wód oceniano według kryteriów zalecanych do oceniania śródlądowych wód powierzchniowych określonych w Rozporządzeniu Ministra Środowiska z dnia 11 lutego 2004 r. w sprawie klasyfikacji dla 
prezentowania stanu wód powierzchniowych i podziemnych, sposobu prowadzenia monitoringu oraz sposobu interpretacji wyników i prezentacji stanu tych wód.

\section{DYSKUSJA WYNIKÓW}

Wyniki badań wskaźników jakości wód powierzchniowych basenów portowych Portu Świnoujście za okres 2004 - 2008 wraz z klasyfikacją wartości badanych wskaźników wg kryteriów Rozporządzenia Ministra Środowiska z dnia 11 lutego 2004 r. przedstawiono w tabelach od 1 do 5.

Tabela 1. Wyniki badań wskaźników jakości wód powierzchniowych basenów portowych Portu Świnoujście w 2004 roku wraz z klasyfikacją wartości badanych wskaźników wg kryteriów

Rozporządzenia Ministra Środowiska z dnia 11 lutego 2004 r.

\begin{tabular}{|c|c|c|c|c|c|}
\hline \multirow{2}{*}{ Badany basen } & \multicolumn{5}{|c|}{ Wskaźnik jakości wód (jednostki) } \\
\cline { 2 - 6 } & $\begin{array}{c}\mathrm{pH} \\
\text { (jedn. } \mathrm{pH})\end{array}$ & $\begin{array}{c}\text { Temperatura } \\
\text { wody }\left({ }^{\circ} \mathrm{C}\right)\end{array}$ & $\begin{array}{c}\mathrm{NO}_{3}^{-} \\
\left(\mathrm{mgN}^{-} \mathrm{dm}^{-3}\right)\end{array}$ & $\begin{array}{c}\mathrm{PO}_{4}{ }^{3-} \\
\left(\mathrm{mg} \mathrm{PO}_{4} \mathrm{dm}^{-3}\right)\end{array}$ & $\begin{array}{c}\mathrm{P}_{\mathrm{og}} \\
\left(\mathrm{mg} \mathrm{P}^{\prime} \mathrm{dm}^{-3}\right)\end{array}$ \\
\hline Atlantycki & $7,82(\mathrm{I})$ & $13,6(\mathrm{I})$ & $2,68(\mathrm{I})$ & $0,47(\mathrm{III})$ & $0,51(\mathrm{III})$ \\
\hline Bałtycki & $7,88(\mathrm{I})$ & $15,2(\mathrm{I})$ & $3,52(\mathrm{I})$ & $0,36(\mathrm{II})$ & $0,73(\mathrm{IV})$ \\
\hline Trymerski & $7,94(\mathrm{I})$ & $15,0(\mathrm{I})$ & $4,92(\mathrm{I})$ & $0,54(\mathrm{III})$ & $0,54(\mathrm{III})$ \\
\hline
\end{tabular}

Objaśnienia: I, III, V - klasyfikacja wartości badanego wskaźnika wg kryteriów Rozporządzenia Ministra Środowiska z dnia 11 lutego 2004 r.

Tabela 2. Wyniki badań wskaźników jakości wód powierzchniowych basenów portowych Portu Świnoujście w 2005 roku wraz z klasyfikacją wartości badanych wskaźników wg kryteriów

Rozporządzenia Ministra Środowiska z dnia 11 lutego 2004 r.

\begin{tabular}{|c|c|c|c|c|c|}
\hline \multirow{2}{*}{ Badany basen } & \multicolumn{5}{|c|}{ Wskaźnik jakości wód (jednostki) } \\
\cline { 2 - 6 } & $\begin{array}{c}\mathrm{pH} \\
\text { (jedn. } \mathrm{pH})\end{array}$ & $\begin{array}{c}\text { Temperatura } \\
\text { oody }\left({ }^{\circ} \mathrm{C}\right)\end{array}$ & $\begin{array}{c}\mathrm{NO}_{3}{ }^{-} \\
\left(\mathrm{mgN}_{\mathrm{dm}}{ }^{-3}\right)\end{array}$ & $\begin{array}{c}\mathrm{PO}_{4}{ }^{3-} \\
\left(\mathrm{mg} \mathrm{PO}_{4} \mathrm{dm}^{-3}\right)\end{array}$ & $\begin{array}{c}\mathrm{P}_{\mathrm{og}} \\
\left(\mathrm{mg} \mathrm{P}^{-3} \mathrm{dm}^{-3}\right)\end{array}$ \\
\hline Atlantycki & $7,97(\mathrm{I})$ & $15,1(\mathrm{I})$ & $3,98(\mathrm{I})$ & $0,72(\mathrm{IV})$ & $0,52(\mathrm{III})$ \\
\hline Bałtycki & $7,78(\mathrm{I})$ & $15,0(\mathrm{I})$ & $2,76(\mathrm{I})$ & $0,47(\mathrm{III})$ & $0,71(\mathrm{IV})$ \\
\hline Trymerski & $7,96(\mathrm{I})$ & $14,7(\mathrm{I})$ & $4,41(\mathrm{I})$ & $0,32(\mathrm{II})$ & $0,58(\mathrm{III})$ \\
\hline
\end{tabular}

Objaśnienia: I, II, III, IV, V - klasyfikacja wartości badanego wskaźnika wg kryteriów Rozporządzenia Ministra Środowiska z dnia 11 lutego 2004 r.

Tabela 3. Wyniki badań wskaźników jakości wód powierzchniowych basenów portowych Portu Świnoujście w 2006 roku wraz z klasyfikacją wartości badanych wskaźników wg kryteriów Rozporządzenia Ministra Środowiska z dnia 11 lutego 2004 r.

\begin{tabular}{|c|c|c|c|c|c|}
\hline \multirow{2}{*}{ Badany basen } & \multicolumn{5}{|c|}{ Wskaźnik jakości wód (jednostki) } \\
\cline { 2 - 6 } & $\begin{array}{c}\mathrm{pH} \\
(\mathrm{jedn} . \mathrm{pH})\end{array}$ & $\begin{array}{c}\text { Temperatura } \\
\text { wody }\left({ }^{\circ} \mathrm{C}\right)\end{array}$ & $\begin{array}{c}\mathrm{NO}_{3}^{-} \\
\left(\mathrm{mgN}^{-} \mathrm{dm}^{-3}\right)\end{array}$ & $\begin{array}{c}\mathrm{PO}_{4}{ }^{3-} \\
\left(\mathrm{mg} \mathrm{PO}_{4} \mathrm{dm}^{-3}\right)\end{array}$ & $\begin{array}{c}\mathrm{P}_{\mathrm{og}} \\
\left(\mathrm{mg} \mathrm{P} \mathrm{dm}^{-3}\right)\end{array}$ \\
\hline Atlantycki & $7,94(\mathrm{I})$ & $15,0(\mathrm{I})$ & $4,28(\mathrm{I})$ & $0,52(\mathrm{III})$ & $0,52(\mathrm{III})$ \\
\hline Bałtycki & $7,91(\mathrm{I})$ & $15,3(\mathrm{I})$ & $4,82(\mathrm{I})$ & $0,74(\mathrm{IV})$ & $0,48(\mathrm{III})$ \\
\hline Trymerski & $7,86(\mathrm{I})$ & $14,5(\mathrm{I})$ & $3,63(\mathrm{I})$ & $0,58(\mathrm{III})$ & $0,78(\mathrm{IV})$ \\
\hline
\end{tabular}

Objaśnienia: I, II, IV, V - klasyfikacja wartości badanego wskaźnika wg kryteriów Rozporządzenia Ministra Środowiska z dnia 11 lutego 2004 r. 
Tabela 4. Wyniki badań wskaźników jakości wód powierzchniowych basenów portowych Portu Świnoujście w 2007 roku wraz z klasyfikacją wartości badanych wskaźników wg kryteriów Rozporządzenia Ministra Środowiska z dnia 11 lutego 2004 r.

\begin{tabular}{|c|c|c|c|c|c|}
\hline \multirow{2}{*}{ Badany basen } & \multicolumn{5}{|c|}{ Wskaźnik jakości wód (jednostki) } \\
\cline { 2 - 6 } & $\begin{array}{c}\mathrm{pH} \\
\text { (jedn. } \mathrm{pH})\end{array}$ & $\begin{array}{c}\text { Temperatura } \\
\text { wody }\left({ }^{\circ} \mathrm{C}\right)\end{array}$ & $\begin{array}{c}\mathrm{NO}_{3}^{-} \\
\left(\mathrm{mgN}^{-} \mathrm{dm}^{-3}\right)\end{array}$ & $\begin{array}{c}\mathrm{PO}_{4}{ }^{3-} \\
\left(\mathrm{mg} \mathrm{PO}_{4} \mathrm{dm}^{-3}\right)\end{array}$ & $\begin{array}{c}\mathrm{P}_{\mathrm{og}} \\
\left(\mathrm{mg} \mathrm{P}^{-3} \mathrm{dm}^{-3}\right)\end{array}$ \\
\hline Atlantycki & $7,85(\mathrm{I})$ & $15,0(\mathrm{I})$ & $3,78(\mathrm{I})$ & $0,47(\mathrm{III})$ & $0,38(\mathrm{II})$ \\
\hline Bałtycki & $7,94(\mathrm{I})$ & $14,5(\mathrm{I})$ & $2,59(\mathrm{I})$ & $0,59(\mathrm{III})$ & $0,59(\mathrm{III})$ \\
\hline Trymerski & $7,93(\mathrm{I})$ & $14,7(\mathrm{I})$ & $4,40(\mathrm{I})$ & $0,52(\mathrm{III})$ & $0,72(\mathrm{IV})$ \\
\hline
\end{tabular}

Objaśnienia: I, III, IV, V - klasyfikacja wartości badanego wskaźnika wg kryteriów Rozporządzenia Ministra Środowiska z dnia 11 lutego 2004 r.

Tabela 5. Wyniki badań wskaźników jakości wód powierzchniowych basenów portowych Portu Świnoujście w 2008 roku wraz z klasyfikacją wartości badanych wskaźników wg kryteriów

Rozporządzenia Ministra Środowiska z dnia 11 lutego 2004 r.

\begin{tabular}{|c|c|c|c|c|c|}
\hline \multirow{2}{*}{ Badany basen } & \multicolumn{5}{|c|}{ Wskaźnik jakości wód (jednostki) } \\
\cline { 2 - 6 } & $\begin{array}{c}\mathrm{pH} \\
(\text { jedn. } \mathrm{pH})\end{array}$ & $\begin{array}{c}\text { Temperatura } \\
\text { ody }\left({ }^{\circ} \mathrm{C}\right)\end{array}$ & $\begin{array}{c}\mathrm{NO}_{3}^{-} \\
\left(\mathrm{mgN}^{-} \mathrm{dm}^{-3}\right)\end{array}$ & $\begin{array}{c}\mathrm{PO}_{4}^{3-} \\
\left(\mathrm{mg} \mathrm{PO}_{4} \mathrm{dm}^{-3}\right)\end{array}$ & $\begin{array}{c}\mathrm{P}_{\mathrm{og}} \\
\left(\mathrm{mg} \mathrm{P}^{-} \mathrm{dm}^{-3}\right)\end{array}$ \\
\hline Atlantycki & $7,92(\mathrm{I})$ & $14,2(\mathrm{I})$ & $2,49(\mathrm{I})$ & $0,37(\mathrm{II})$ & $0,51(\mathrm{III})$ \\
\hline Bałtycki & $7,89(\mathrm{I})$ & $15,0(\mathrm{I})$ & $4,81(\mathrm{I})$ & $0,62(\mathrm{III})$ & $0,54(\mathrm{III})$ \\
\hline Trymerski & $7,88(\mathrm{I})$ & $14,4(\mathrm{I})$ & $4,70(\mathrm{I})$ & $0,54(\mathrm{III})$ & $0,42(\mathrm{III})$ \\
\hline
\end{tabular}

Objaśnienia: I, III, IV, V - klasyfikacja wartości badanego wskaźnika wg kryteriów Rozporządzenia Ministra Środowiska z dnia 11 lutego 2004 r.

Wody basenów portowych Portu Świnoujście w okresie prowadzonych badań posiadały wartości $\mathrm{pH}$ były lekko zasadowe - w całym okresie badawczym zostały zaliczane do I klasa jakości wód wg kryteriów Rozporządzenia Ministra Środowiska z dnia 11 lutego 2004 r. W ekosystemach wodnych badanych basenów badana wartość $\mathrm{NO}_{3}{ }^{-}$kształtowała się głównie na poziomie dla wód I klasy jakości, natomiast wartości $\mathrm{PO}_{4}{ }^{3-} \mathrm{i} \mathrm{P}_{\mathrm{og}}$. kształtowały się na poziomie dla wód III i IV klasy jakości. W całym okresie badawczym tj. $2004-2008$ wody basenów portowych Portu Świnoujście posiadały wskaźniki oceny jakości wód od I klasy do IV klasy jakości.

\section{WNIOSKI}

Z uwagi na narażenie basenów portowych Portu Świnoujście na zanieczyszczenia związane z przeładunkami jakie odbywają się na jego terenie zboża, rud, olejów, celulozy, drobnicy węgla, żelaza, należy prowadzić badania oceny jakości wód tych basenów, aby można na bieżąco ocenić stan wód tych akwenów.

\section{Polskie Normy}

PN/C-04540.03. Badania wartości pH, kwasowości i zasadowości. Oznaczanie kwasowości i zasadowości mineralnej i ogólnej metodą miareczkowania wobec wskaźników. 
PN/C-04537.02. Oznaczanie rozpuszczonych ortofosforanów kolorymetryczną metodą molibdenianową z chlorkiem cynawym jako reduktorem.

PN/C-04537.09. Woda i ścieki. Badania zawartości związków fosforu. Oznaczenie fosforu ogólnego.

PN/C-04576.09. Oznaczanie azotu azotanowego metodą kalorymetryczną z p-fluorofenolem.

PN/C-04632.03. Ogólne zasady pobierania próbek do badań fizycznych, chemicznych i biologicznych. Technika pobierania próbek.

PN/C-04632.04. Ogólne zasady pobierania próbek do badań fizycznych, chemicznych i biologicznych. Utrwalanie i przechowywanie próbek.

PN/C-06504. Przygotowanie roztworów buforowych.

\section{References}

[1] Barik S.K., Purushothaman C.S., Mohanty A.N., Aquacult. Res. 32 (2001) 819-832.

[2] Bowden K. F., Oceanic and Estuarine Mixing Processes, Riley J. P., Skirrow G. (eds.), Chemical Oceanography, London - New York - San Francisco, (1974) 1-41.

[3] Buchholz W., Zmienność stanów i przepływów w ujściach rzek na przykładzie ujścia Odry, Materiały Sesji Naukowej KBM PAN. Szczecin 1990, 49-70.

[4] Buchholz W., Materiały do monografii Dolnej Odry. Warunki hydrologicznohydrodynamiczne, Prace IBW PAN, Gdańsk, 22 (1990) 1-117

[5] Daniszewski P., International Letters of Chemistry, Physics and Astronomy 1 (2012) 6-12.

[6] Daniszewski P., International Letters of Chemistry, Physics and Astronomy 1 (2012) 13-16.

[7] Daniszewski P., International Letters of Chemistry, Physics and Astronomy 2 (2012) 42-45.

[8] Daniszewski P., International Letters of Chemistry, Physics and Astronomy 2 (2012) 46-52.

[9] Daniszewski P., International Letters of Chemistry, Physics and Astronomy 2 (2012) $35-41$.

[10] Demel K., Życie morza. Gdańsk, 1974.

[11] Dojlido J. R., Chemia wód powierzchniowych, Wydawnictwo Ekonomia i Środowisko 1995.

[12] Druet C., Elementy hydrodynamiki geograficznej, Warszawa 1995.

[13] Elbanowska H., Zerbe J., Siepak J. Fizyczno-chemiczne badania wód, Wydawnictwo Naukowe PWN 1999, ss. 232.

[14] Grasshoff K., Methods of Seawater Analysis, Weinheim - New York, 1976.

[15] Hermanowicz W., Dojlido J., Dożańska W., Koziorowski B., Zerbe J., Fizycznochemiczne badanie wody i ścieków, Arkady, Warszawa 1999. 
[16] Jasińska E., Dynamika słonych wód w estuariach polskich rzek, Inst. Budownictwa Wodnego PAN 24 (1991) 1-206.

[17] Kajak Z., Hydrobiologia-Limnologia. Ekosystemy wód śródlądowych, PWN, Warszawa 1998, ss. 355.

[18] Leybovich S., Ulrich D., J. Geophys. Res. 77 (1972) 1683-1688.

[19] Lyman J. Chemical consideration, physical and chemical properties of sea water. Washington, cited after: Monin A. S., (red.), 1979, Chimija okieana. T. 1, Chimija wod okieana, Moskwa 1959.

[20] Majewski A., (red.), Zalew Szczeciński, Warszawa 1980.

[21] Majewski A., Charakterystyka hydrologiczna estuaryjnych wód u polskiego wybrzeża, Prace PIHM, 105 (1972) 3-37.

[22] Majewski A., Charakterystyka hydrologiczna Zatoki Pomorskiej, Warszawa 1974.

[23] Mikulski Z., Udział wód rzecznych w stosunkach hydrologicznych Zalewu Szczecińskiego, Biul. PIHM, 5 (1960) 1-23.

[24] Mikulski Z., Wody śródlądowe w strefie brzegowej południowego Bałtyku, Biul. PIHM 1970.

[25] Młodzińska Z., Zawartość tlenu. W: Majewski A. (red.), Zalew Szczeciński, Warszawa, (1980), 223-230.

[26] Młodzińska Z., Hydrochemia, W: Majewski A. (red.), Zalew Szczeciński, Warszawa, (1980), 248-277.

[27] Port Szczecin. Informacja ogólne. Urząd Morski w Szczecinie. 2009.

[28] Port w Szczecinie nabrzeża. Zarząd Morskich Portów Szczecin i Świnoujście SA. 2009.

[29] Ryszard Kotla, Z dziejów szczecińskiego portu. „Magazyn Portowy”. 1/2007, s. 32, 2007. 